\title{
Becoming a first-class research university through creative innovation
}

After half a century of focussed hard work, the University of Science and Technology of China (USTC) recently celebrated the 50th anniversary of its founding. President Hu Jingtao sent a congratulatory letter, encouraging USTC to strengthen its sense of mission and responsibility, to aim for cutting edge scientific and technological research, to serve China's strategic development needs, to creatively teach and research and to do all possible to build a world-class research university.

As a new style science and technology university established under the auspices of the Chinese Academy of Sciences, ever since its foundation in 1958, USTC has progressed in step with China's development, upholding the principle of Reatively Teach and Research and Serve China with Science and Technology, as well as continuing the tradition of using Science with Practice. In order to meet the requirement of our first president, GUO Moruo, of Placing "Equal Importance on Ability and Integrity" and "Producing Both Talent and Results", USTC in all respects sought excellence and emphasizing content-based development and all-around cultivation, thereby graduating numerous top-level professionals and a series of original, world-class achievements in science and technology. USTC did all possible to contribute to China's educational development and socialist modernization.

From its foundation, USTC supported China's major national strategic demands represented in the late 1950s by the concept of "Two Bombs and a Satellite". It did so by establishing science and technology programs and departments for what were then newly-emerging or even non-existent fields, inviting leading scientists from the Chinese Academy of Sciences to teach fundamental courses, combining teaching with research, science with technology and theory with practice. Great importance was placed on the instruction of foundation courses, in order to cultivate outstanding professionals in nascent, peripheral and cross-disciplinary fields by offering them broadly-disciplined curricula with high academic standards. In the beginning of the period of Reforms and Opening up to the Outside World, USTC initiated and implemented a series of innovative and far-sighted educational reforms, instituting a Class for Gifted Young People, implementing an academic credit system, establishing China's first ever graduate school, and building the first national mega-science project in any Chinese university, thereby serving in the vanguard of China's higher education reforms. Since the 1990s, USTC has carried out in succession China's national Project 211. Project 985 and the Project of Knowledge Innovation, actively instituted educational reforms in response to China's changing requirements, considered and decided on a 
new mode for cultivating innovative talents, and restructured its academic disciplines in line with international scientific and technological standards, achieving noteworthy advances in quantum information, nano-technology, the life sciences and in various other fields.

In order to celebrate the 50th anniversary of the founding of USTC and to introduce the academic advances made in recent years, and at the invitation of Academician XIA Jianbai, Editor-in-chief of the Chinese Science Bulletin, USTC requested leading researchers from such key research establishments as the National Synchrotron Radiation Laboratory, the Hefei National Laboratory for Physical Sciences at the Microscale, the State Key Laboratory of Fire Science, the National High Performance Computing Center at Hefei, as well as the Mengcheng National Geophysical Observatory Station, and well-known professors from various USTC departments, to contribute to a Special Edition of the "Chinese Science Bulletin" in order to honor USTC's 50th Anniversary. The Special Edition will be published in two versions, Chinese and English, respectively containing 27 and 25 articles. These articles report on advances made in the fields of quantum information, single molecular science, high-temperature superconductors, nano technology, the life sciences, fire science, high-power computing, the earth and environmental sciences and new energy sources.

The Chinese Science Bulletin is one of China the most respected journals of fundamental and theoretical research in the natural sciences, and has published a large number of world-class research results. To enhance academic exchange in and outside of China and to promote the development of China's science and research, USTC, in cooperation with the Chinese Science Bulletin presents this special edition in order to make USTC more widely known through its academic research attainments, thus opening a window on USTC for readers in China and abroad, to enhance international cooperation and friendship between USTC and research scientists throughout the world.

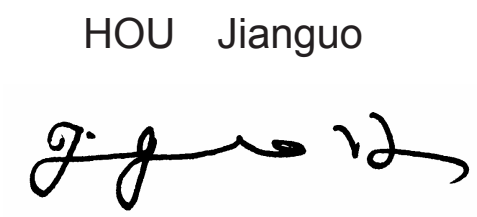

President, University of Science and Technology of China Academician of Academia Sinica

doi: $10.1007 / s 11434-009-0414-x$ 